\title{
Thinking about a medical school core curriculum for medical ethics and law
}

\author{
Raanan Gillon Imperial College of Science, Technology and Medicine, University of London
}

The advice in this issue of geneticist Professor Bob Williamson' ${ }^{\prime}$ on the teaching of medical ethics to medical students is timely and challenging. The United Kingdom medical schools have all been advised by the General Medical Council (GMC) to review their medical curriculum.' Various changes are recommended, including a rigorous pruning of all unnecessary rote leaning, an interdisciplinary approach to teaching, an emphasis on student self-motivation and inquiry, earlier patient contact rather than the current "preclinical" and "clinical" dichotomy in the syllabus, a clear distinction between core content which every medical student must acquire, and a large menu of optional subjects from which students should be allowed to choose their preferred selection of "special study modules"; and a recommendation that medical ethics and medical law should become part of the core syllabus that every student must study.

As a result of the GMC recommendations, working parties, committees, individual teachers, medical education units and deans, are busy reorganising their syllabuses. One of the common enterprises is trying to work out what should be the content of a core curriculum in medical ethics and medical law, what should be offered as options to be done in special study modules, how these subjects should be taught and how the effectiveness of such teaching and learning should be assessed.

Rather than each medical school group inventing or re-inventing - the wheel would it not be worthwhile for representatives from medical schools to get together and try to establish some mutually agreed core contents in medical ethics and medical law? In America, where the development of academic bioethics teaching in medical schools started in the 1970s, well ahead of the rest of the world, a conference of some of the leaders in the field of bioethics was convened in 1983 in order to try and agree "basic curricular goals". In the New England fournal of Medicine paper that resulted ${ }^{3}$ this "DeCamp Conference" made a variety of proposals that might afford a useful starting point.

Most importantly, the conference recommended that the basic medical ethics curriculum "should be centred on the kinds of moral problems that physicians encounter most frequently in practice rather than on sensational cases of the type that occur only rarely". It should aim to address several kinds of learning in medical ethics. First was clarification of important concepts in medical ethics (for example competence to consent, consent itself, confidentiality). The second was an understanding of ethically important decisionmaking procedures (for example deciding when it is morally justified to impose treatment on an unwilling patient). The third was acquisition of the ability to apply concepts and decision-making procedures in real cases, linked to which was an important fourth type of learning - the acquisition of sufficient "interactional skills" (what might now be called communications skills) to be able to apply their theoretical knowledge "sensitively and humanely".

The group were in no doubt that althougg medical ethics should be taught throughout the cue riculum "[a] portion of the curriculum must be sef aside in which teachers with explicit training i medical ethics can present a coherent overview of the field". While some of the conceptual and theoretical content of medical ethics could be taught through reading and lectures, small-group discussion was essential, students needing repeated opportunities to practise and be supervised in applying their theoretical learning to actual clinical problems.

It should be acknowledged from the start that medical ethics teaching was not intended to improve the moral character of student doctors, but rather to provide those of sound moral character who had been selected to become medical students "with the intellectual tools and interactional skills to give that moral character its best behavioural expression". The DeCamp group recommended that medical ethics teaching should be both intellectually rigorous and "emotionally supportive and facilitating"; it should acknowledge disagreement as well as agreement in the important topics of medical ethics; and it should be interdisciplinary: "Only rarely are clinicians sufficiently trained in ethics and do ethicists have sufficient clinical knowledge and experience to teach alone competently".

So far as the contents of a core curriculum were concerned the DeCamp group recommended relatively few elements, indicating briefly the associated legal aspects that they believed also ought to be taught. The first was the ability to identify moral aspects of medical practice, and they pointed out that because doctors were fundamentally committed to ameliorating the harms caused by illness, often by 
using interventions that themselves, could cause harms, there was a moral aspect to almost all aspects of medical practice, though this often went unnoticed because it was uncontroversial.

Next, medical students should be taught because doctors should know - about valid consent, what it is, and how to obtain it in an uncoercive, though not necessarily unpersuasive, manner. They should know how to proceed if a patient is only partially competent, or incompetent, to consent to or refuse treatment, and they should know about the relevant legal considerations. They should know about the moral and legal relevance of the views of next of kin in various such decisions, and also about how to proceed when there are no next of kin.

Medical students should be taught - because doctors should know - how to deal with refusal of treatment, and in which circumstances and why refusal may be justifiably overridden, again knowing the relevant legal considerations. Students should also be able to decide when and why it is morally justified to withhold information from patients, and be able to apply these justifications in those "rare cases [where] it may be morally justified to withhold such information". Similarly they should be taught the ability to decide when it is morally justified to breach confidentiality, they should know the relevant law, and they should be able to distinguish in actual cases those situations where it is justified and where it is not justified.

In the care of patients with poor prognoses or who are terminally ill, students should "know and understand ethical concepts and principles sufficiently to manage", they should have learned the necessary interactional skills, and be abreast of the relevant law. They should also know "with whom and when it is morally justified to discuss limiting some forms of treatment for a patient" (including decisions not to resuscitate) and again the relevant law.

These were the core issues agreed to be necessary to a core syllabus in medical ethics. Some but not all of the DeCamp group also believed that knowledge of issues in equitable distribution of health care should be regarded as essential to a core curriculum; while about half of the group believed that consideration of abortion should also be part of the core curriculum.

It would be unlikely that any medical school in a country with "socialised medicine" - ie with some sort of a national health service - would be ready to exclude the elements of equitable distribution of inadequate health care resources from core subject status for medical ethics: in such a country they would almost certainly be regarded as necessary for the contemporary education of every student doctor. And since every UK medical student passes through a period of training in obstetrics and gynaecology where abortion is a commonplace operation, it would surely be very odd if any British equivalent of the DeCamp group were to exclude consideration of the moral issues of abortion from the medical ethics and law core curriculum.
Indeed such a group might wish to add to the core other moral and legal issues that students are bound to encounter clinically during their time at medical school: basic standards of good medical care and how failing to meet them constitutes moral and legal negligence; the moral relationship between ordinary clinical practice and different sorts of medical research, and related moral conflicts and their resolution; conflicts between the Hippocratic obligation to do the best possible for a particular patient and a range of other potentially incompatible moral obligations, whether to other patients, to oneself, to one's family, or to society. In this context differences in moral emphasis between ordinary clinical practice and public health, health promotion and disease prevention might be regarded as appropriate elements of the core ethics curriculum. Similarly the General Medical Council's concern, in Tomorrow's Doctors, ${ }^{2}$ with moral issues arising from a pluralist society, including the social and professional obligations to respect without prejudice patients and colleagues of varying backgrounds, cultures and ways of life, might also be candidates for core content in the ethical education of medical students. So too might a basic knowledge of the ethical norms of the profession as stated by the General Medical Council in its advice to doctors, now known as Duties of a Doctor (and superseding "the little blue book" of yesters year).

Such a conference might wish to try to group the्य content of an agreed core syllabus in medical ethics and law into currently recommended pedagogic categories of "knowledge, skills and attitudes". It might also address the thorny issues of teaching methods even if a core syllabus were agreed, it is by no means clear which are the most effective methods for ensuring its acquisition, retention and use by medical students: and the equally thorny issues of assessment, for again, optimal methods of examining students in this area have not been established. In these last two areas such a conference might prefer to recommend experiments with a wide range of alternative approaches.

These are exciting times for the teaching of medical ethics and law in medical schools - they will surely prove most fruitful for tomorrow's doctors, and more importantly for tomorrow's patients, if they are approached in a spirit of cooperation, openmindedness and academic inquiry.

\section{References}

1 Williamson B. Medical ethics, teaching and the new genetics. Fournal of Medical Ethics 1996; 22: 325-6.

2 General Medical Council. Tomorrow's doctors. London: GMC, 1993.

3 Culver, CM, Clouser KD, Gert B, Brody H, Fletcher J, Jonsen A, et al. Basic curricular goals in medical ethics. New England fournal of Medicine, 1985; 312: 253-6.

4 General Medical Council. Duties of a doctor - (a set of booklets). London: GMC, 1995. 